\title{
LYMPHOCYTE-NEUTROPHIL RATIO IN THE DIAGNOSIS OF TUBERCULAR PLEURAL EFFUSION IN A TERTIARY CARE CENTRE: A DESCRIPTIVE CROSS SECTIONAL STUDY
}

\author{
Rajneesh $\mathrm{Jha}^{1^{*}}$, Ram Kumar Mehata ${ }^{2}$ Puru Koirala ${ }^{3}$
}

\section{Affiliation}

1. Assistant Professor, Department of Internal Medicine, Birat Medical College and Teaching Hospital, Nepal

2. Lecturer, Department of Internal Medicine, Birat Medical College and Teaching Hospital, Nepal

3. Associate Professor, Department of Internal Medicine, Birat Medical College and Teaching Hospital, Nepal, Nepal

\section{ARTICLE INFO}

Received : 04 March, 2021

Accepted : 28 July, 2021

Published : 04 November 2021

(C) Authors retain copyright and grant the journal right of first publication with the work simultaneously licensed under Creative Commons Attribution License CC - BY 4.0 that allows others to share the work with an acknowledgment of the work's authorship and initial publication in this journal.

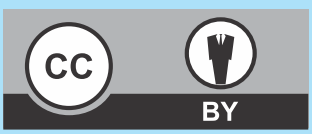

ORA 262

DOI: https://doi.org/10.3126/bjhs.v6i2.40351

\section{* Corresponding Author}

Dr. Rajneesh Jha

Assistant Professor

Department of Internal Medicine

Birat Medical College and Teaching Hospital, Nepal

Email: jha_rajneesh@yahoo.com

ORCID: https://orcid.org/0000-0003-4921-7801

\section{Citation}

Rajneesh Jha, Ram Kumar Mehata, Puru Koirala. LymphocyteNeutrophil Ratio in the Diagnosis of Tubercular Pleural Effusion in a Tertiary Care Centre: A Descriptive Cross Sectional Study. BJHS 2021;6(2)15. 1517-1521.

\section{ABSTRACT}

\section{Introduction}

Tuberculosis is a common infection in our community. Tubercular pleural effusion is the second most common form of extrapulmonary tuberculosis. Among the several causes of exudative pleural effusison tubercular remains the most common form in clinical practice. The aim of this study was to evaluate the significance of lymphocyte-neutrophil ratio( $L N$ ratio) in cases of exudative effusion for diagnosis of tubercular effusion.

\section{Methodology}

This was a hospital based cross sectional study done in Patients at tertiary care hospital from $1^{\text {st }}$ September 2020 to $1^{\text {st }}$ april 2021 after taking ethical clearance from institutional reviw committee. Convienience sampling was done. Statistical Analysis of data like percentages and frequencies were used for categorical variables. Mean and SD (standard deviation) were used for describing continuous variables. Inferential statistical tools like Chi-Square test and Student's t-test were used. P-value of $<0.05$ was considered statistically significant.

\section{Result}

out of 200 cases $75 \%$ were tubercular pleural effusion and these cases were found have high levels of LN ratio $(0.89 \pm$ 0.11 for females and $0.97 \pm 0.14$ for males) and ADA (137.79 \pm 44.61 for females and $147.61 \pm 51.64$ for males) and more than $90 \%$ sensitivity and specificity of $L N$ ratio and ADA level.

\section{Conclusion}

Exudative pleural fluid $\mathrm{L} / \mathrm{N}$ ratio $>0.75$ is an efficient means of diagnosing tuberculous pleural effusion and its combination with ADA level gives us more accuracy and surety about the diagnosis of tubercular pleural effusion.

\section{KEYWORDS}

$L N$ ratio, $A D A$, exudative effusion. 


\section{INTRODUCTION}

Pleural effusion is defined as the abnormal collection of fluid in the pleural cavity. It is classified into transudates and exudates based on the Light's criteria. ${ }^{1}$ Common causes of exudative pleural effusions found in clinical practices are tuberculosis, para pneumonic, malignancy primary or metastasis, associated with collagen vascular disease, liver abscess, subphrenic abscess, pancreatitis. ${ }^{2}$ Tuberculous pleural effusion is seen in many cases in our region. Tuberculosis has high prevalence in asian countries like Nepal anad India. It is the one of the most common form of extra pulmonary tuberculosis. ${ }^{3}$

It becomes challenging for a clinician many a times to diffrentiate the causes for pleural effusion. First of all we have to differentiate transudative effusion from exudative effusion. Then it is essential to find out diagnosis for underlying cause of exudative effusion. For this purpose several biochemical parameters like adenosine deaminase (ADA), lactate dehydrogenase (LDH), C-reactive protein (CRP), interferon gamma and procalcitonin levels, have been studied, but its diagnosis is still challenging. ${ }^{4-6}$ However adenosine deaminase (ADA) is being frequently used as a diagnostic maker in tuberculous pleural effusion in many centres in our region. ADA derived from the summary receptor operator curve with cut off value $>40 \mathrm{U} / \mathrm{L}$ is found to be more than $90 \%$ both sensitivite and specific. ${ }^{7-8}$ Lymphocyte- $^{-}$ neutrophil ratio (LN ratio) is being investigated as novel inflammatory marker nowadays. The association of lymphocyte-neutrophil ratio and lung cancer has been mostly investigated among studies on lung diseases, and a few studies have investigated its values in the pleural fluid for the differential diagnosis of bacterial pneumonia and tuberculous pleural effusion. ${ }^{9-10}$

Aim of the study was to find out the role of the lymphocyte neutrophil ratio (LNR) which can be easily obtained by determining the total and differential cell counts of pleural fluid for the diagnosis of exudative pleural effusion as tubercular in origin.

\section{METHODOLOGY}

It was a single centre hospital based descriptive cross sectional study. It was conducted in Birat medical college and teaching hospital, biratnagar, Nepal from September $1^{\text {st }}$ 2020 to april $1^{\text {st }} 2021$. The study included 200 patients aged more than 15 years giving consent to be enrolled in the study. Prior to the the study ethical clearance was taken from IRC. Sample size calculation was obtained by using the formula,

Sample Size $(N)=(1.96)^{2} \times P(1-P) / M^{2}$

Where, $\mathrm{P}=$ Prevalence of the disease in the locality; $\mathrm{M}=$ Margin of error (5\%) .The prevalence of tuberculous pleural effusion has been reported to be variable in different countries. prevalence varies in asaian and non asian countries. Nepal as an asian country has a higher prevalence reate. Prevalence in asian countries is usually $10-20 \%$ by various studies.(11-12) keeping a prevalence of $15 \%$, the sample size was calculated 196 . So, sample size of 200 was considered in this study.

\section{Inclusion criteria}

- Patients of exudative pleural effusion,

- Age >15years,

- Hemodynamically stable.

\section{Exclusion criteria}

- Patients of transudative pleural effusion,

- Age<15years,

- Hemodynamically unstable.

\section{Diagnostic criteria}

Light's criteria (1) was used to diagnose exudative pleural effusion. Exudative pleural effusion meets at least one of the following criteria

- Pleural fluid / serum protein $>0.5$

- Pleural fluid LDH/serum LDH >0.6,

- Pleural fluid LDH > two-thirds of normal upper limit for serum.

Criteria taken for diagnosis of tuberculous pleural effusion ${ }^{8}$ Demonstration of AFB in pleural fluid by AFB stain or Gene Xpert test and / or ADA $>40 \mathrm{U} / \mathrm{L}$ and / or $\mathrm{L} / \mathrm{N}$ ration $>0.75$ in pleural fluid.

\section{Imaging}

Plain chest X-ray PA view, USG chest and/or CT chest based on afford ability.

Under all aseptic precautions diagnostic thoracocentesis was done, and fluid was sent for analysis of glucose, protein, cytology and cell count, LDH, AFB and gram stain, culture and sensitivity and ADA were done in all cases. Gene Xpert test of pleural fluid was done in selected cases depending upon the availability of test and recommendation by government tuberculosis centre specially in suspected MDR cases and patients who were treated for pulmonary tuberculosis in the past.

In non-tuberculous pleural effusion, evaluation was done for pneumonia, malignancy, metastasis, empyema and rheumatoid pleurisy, liver abscess, pancreatitis. Besides detailed history and clinical examination, the different investigations were carried out like Complete haemogram, ESR, serum Urea, Serum Creatinine, Liver Function Tests, serum ANA, dsDNA, RA factor, serum thyroid function tests, Sputum AFB, Sputum culture and sensitivity depending on the patient history and examination.

The $\mathrm{LN}$ ratio was obtained by dividing the absolute lymphocyte count by the absolute neutrophil count. Total and differential counts were obtained from pleural fluid analysis.

Para-pneumonic effusion was diagnosed based on the presence of clinical symptoms cough, fever, dyspnoea and a radiographic pulmonary infiltrate that recovered with use of antibiotics.

Pleural effusion due to lung primary or secondaries was diagnosed when the pleural fluid cytology and/or pleural biopsy findings were positive for malignancy.

Effusion due to connective tissue disorder like Sustemic lupus erythamtosis was defined as effusion in patients 
positive for ANA and Anti DsDNA.

Pleural effusion aasociated with Pancreatitis was diagnosed as cases with raised amylase and ultrasound abdomen showing evidence of pancreatitis.

Pleural effusion associated with rheumatoid arthritis was diagnosed when it had low glucose, low pH, high LDH and patients positive for RA factor and anti ccp.

Statistical Analysis of data like percentages and frequencies were used for categorical variables. Mean and SD(standard deviation) were used for describing continuous variables. Inferential statistical tools like Chi-Square test and Student's t-test were used. P-value of $<0.05$ was considered statistically significant.

\section{RESULTS}

A total of 200 patients of exudative pleural effusion were analyzed, out of which 124 (62\%) were males and 76(38\%)

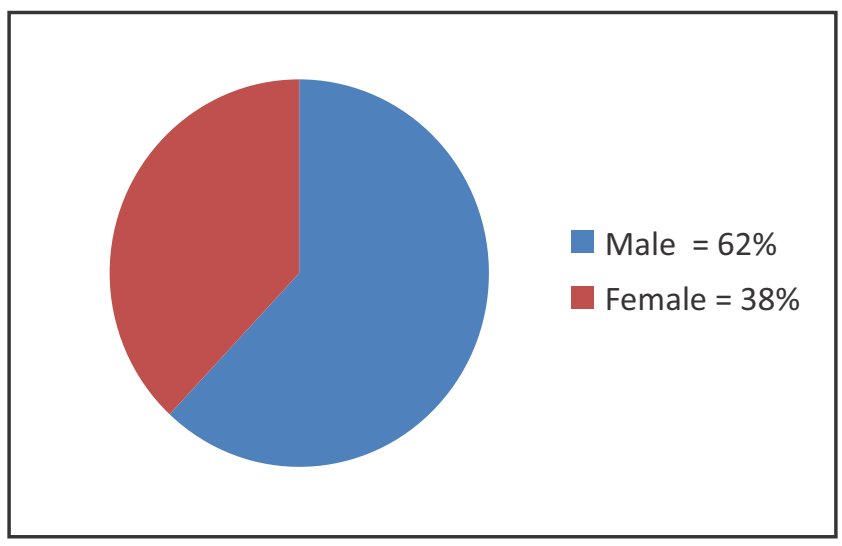

Out of these 200 patients most of them had pleural effusion due to tuberculosis. Other causes were pneumonia, systemic lupus erythematosis, rheumatoid arthritis, pancreatitis, liver abscess, bronchogenic cancer and metastasis to lungs. Males and females were in almost similar proportion among the different groups (diagram2)

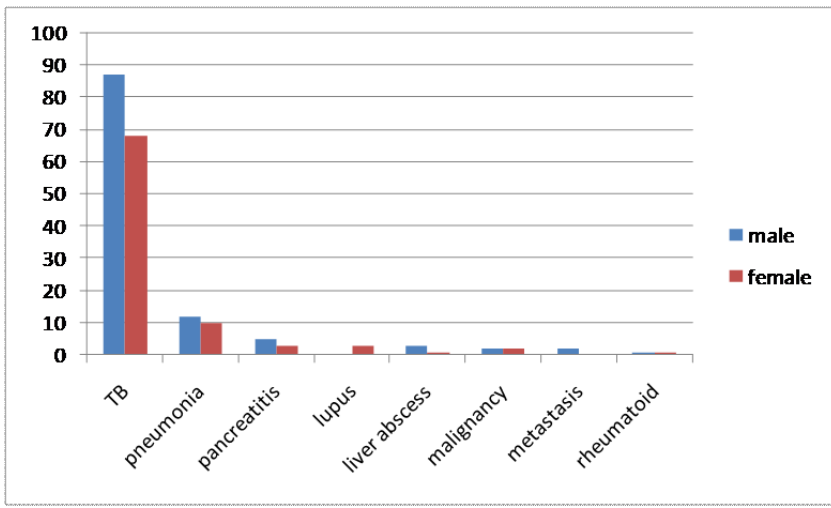

We analysed 200 participant's samples and categorized them into female and male groups so as to further observe the age groups, ADA, LN ratio values. we found different mean values for tuberculous and nontuberculous pleural effusion samples among males and females (table 1 ).

\begin{tabular}{|c|c|c|c|}
\hline Variables & $\begin{array}{l}\text { Nontuberculous } \\
\text { effusion }\end{array}$ & Tuberculous effusion & P-value \\
\hline \multicolumn{4}{|l|}{ Female } \\
\hline Age & $39.04 \pm 13.72$ & $48.55 \pm 15.72$ & N/A \\
\hline ADA & $33.75 \pm 14.13$ & $137.79 \pm 44.61$ & 0.0001 \\
\hline LN ratio & $0.53 \pm 0.16$ & $0.89 \pm 0.11$ & 0.0001 \\
\hline \multicolumn{4}{|l|}{ Male } \\
\hline Age & $40.15 \pm 18.24$ & $41.97 \pm 13.74$ & N/A \\
\hline ADA & $37.46 \pm 15.50$ & $147.61 \pm 51.64$ & 0.0001 \\
\hline LN ratio & $0.45 \pm 0.16$ & $0.97 \pm 0.14$ & 0.0001 \\
\hline
\end{tabular}

When we compared the samples dividing it into two major groups as tuberculous and nontubercoulous we found that most of the tuberculous samples had both ADA $>40 U / L$ and $\mathrm{LN}$ ratio $>0.75$ together while most of the nontuberculous samples had both $A D A<40 U / L$ and $L N$ ratio $<0.75$ together.

\begin{tabular}{|c|c|c|c|}
\hline & $\begin{array}{l}\text { Tuberculous } \\
\text { (n) }\end{array}$ & $\begin{array}{c}\text { Non-Tuberculous } \\
\text { (n) }\end{array}$ & $\begin{array}{c}\text { Total } \\
\text { (n) }\end{array}$ \\
\hline$<40 \mathrm{U} / \mathrm{L}$ ADA and $<0.75 \mathrm{LN}$ ratio & 0 & 38 & 38 \\
\hline$>40 \mathrm{U} / \mathrm{L}$ ADA and $>0.75 \mathrm{LN}$ ratio & 148 & 3 & 151 \\
\hline$<40 \mathrm{U} / \mathrm{L}$ ADA and $>0.75 \mathrm{LN}$ ratio & 0 & 0 & 0 \\
\hline$>40 \mathrm{U} / \mathrm{L}$ ADA and $<0.75 \mathrm{LN}$ ratio & 2 & 9 & 11 \\
\hline
\end{tabular}

Similarly we analysed the ADA levels and LN ratio separately in these two groups and found that maximum number of tuberculous samples had ADA $>40 \mathrm{U} / \mathrm{L}$ and $\mathrm{LN}$ ratio $>0.75$ (tables and diagrams 3 and 4)

\begin{tabular}{|c|c|c|}
\hline & TB & Non-TB \\
\hline$>40 \mathrm{U} / \mathrm{L}$ & 150 & 12 \\
\hline$<40 \mathrm{U} / \mathrm{L}$ & 0 & 38 \\
\hline
\end{tabular}

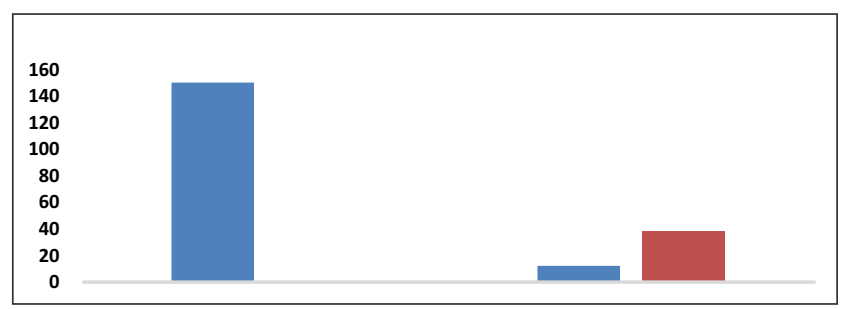

\begin{tabular}{|c|c|c|}
\hline & TB & Non-TB \\
\hline$>0.75 \mathrm{LN}$ ratio & 148 & 3 \\
\hline$<0.75$ LN ratio & 2 & 47 \\
\hline
\end{tabular}

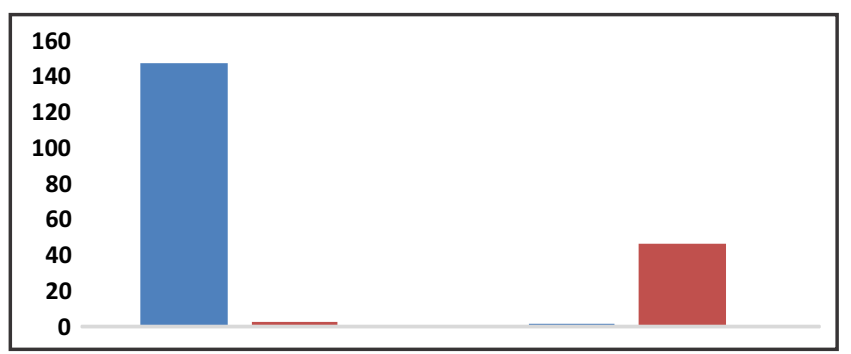

We found very high sensitivity, specificity, PPV, NPV of LN ratio in tuberculous pleural effusion (table-5) 


\begin{tabular}{|c|c|c|c|c|c|}
\hline Table-5 & Sensitivity \% & Specificity \% & PPV \% & NPV \% & $\begin{array}{l}\text { Disease } \\
\text { prevalence }\end{array}$ \\
\hline $\begin{array}{l}\text { ADA level } \\
>40 \mathrm{U} / \mathrm{L}\end{array}$ & 92.6 & 100 & 100 & 76 & 75 \\
\hline $\begin{array}{l}\text { LN ratio } \\
>0.75\end{array}$ & 98 & 95.9 & 98.7 & 94 & 75 \\
\hline
\end{tabular}

\section{DISCUSSION}

Pleural effusion is common respiratory problem in our clinical practice. Many cases with fever, cough, dyspnoea visiting our outpatient department or admitted in medical ward through emergency are found to have pleural effusion. The most common causes of exudative pleural effusion include pneumonia, tuberculosis and cancer .The diagnostic dilemma many a times alter the course of management. Pneumonia responds to limited course of antibiotics, while tuberculosis needs long term antitubercular drugs according to national tuberculosis program while lung cancer has different protocol like surgery, chemo and radiotherapy. Cases like pleural effusion associated with pancreatitis, rheumatoid arthritis, liver abscess respond only when underlyind causes are treated. Hence diagnosis of exudative pleural effusion is of utmost importance. Although many biochemical parameters, such as adenosine deaminase, lactate dehydrogenase, C-reactive protein, adenosine deaminase, interferon gamma and procalciton in levels, have been studied in the context of the diagnosis of exudative pleural effusion, its diagnosis is still challenging.

As we know prevalence of tuberculosis is high in Nepal ${ }^{13}$ and it can present in two forms either pulmonary or extra pulmonary. Tuberculous pleural effusion is one of the most common form of extra pulmonary tuberculosis. ${ }^{14}$ Its diagnosis can be done through pleural fluid analysis via thoracocentesis. Different parameters are analysed in pleural fluid like glucose , protein, cell count, LDH, ADA, malignant cells. ${ }^{15}$ Staining is done with AFB stain, Graham stain. Culture is done for bacteria, tuberculosis. PCR is available for different organisms. But among all, lymphocyte-neutrophil ratio (LN ratio) calculated with cell count is simple, inexpensive and quick method to diagnose tuberculous effusion. AFB staining is very less sensitive, ${ }^{16}$ culture for tuberculosis is not feasible in all centres, PCR is very expensive, not much sensitive for pleural fluid ${ }^{17}$ and also not available in all centres.

In this study, we investigated the cell counts of exudative pleural effusions and these counts' contribution to differential diagnosis by calculating the LN ratio. The pleural fluid LN ratio value was significantly higher in tuberculous effusion compared to nontuberculous effusions. This was similar to the study done by Emet et al.(18)However, LN ratio in malignant, para-pneumonic and other nonmalignant effusions was not significantely different.

In our study, we found that most of the tuberculous pleural effusion samples had both ADA $>40 U / L$ and $L N$ ratio $>0.75$ together while most of the nontuberculous samples had both $A D A<40 U / L$ and $L N$ ratio $<0.75$ together. it shows that $\mathrm{LN}$ ratio had important impact on diagnosis of tuberculous pleural effusion besides ADA level. This was similar to the study done by Lesley J. et al. ${ }^{19}$

In this present study, $75 \%$ of the pleural effusion cases were tubercular in origin and all of them had ADA level was $\geq 40 \mathrm{U} / \mathrm{L}$ which correlates well with the study done by Ocaña let $a l,{ }^{20}$ in which they stated that adenosine Deaminase level $>40 \mathrm{IU} / \mathrm{L}$ has very high diagnostic value in pleural effusion.

Similarly, among the tubercular effusion cases $98 \%$ had LN ratio $>0.75$ which correlates well with the study done by luisveldes et $\mathrm{al}^{21}$ in which they found that more than $95 \%$ tubercular effusion had $>50 \%$ lymphocytes.

Our study shows high sensitivity and specificity of LN ratio similar to ADA. When patients of exudative pleural effusion are evaluated in opd and wards we always send ADA as a diagnostic parameter. With a cut off value of more than 40 $\mathrm{IU} / \mathrm{ML}$, exudative pleural effusion are diagnosed as tubercular in origin. Since LN ratio is found to have similar sensitivity and specificity itclarifies that $L N$ ratio has high diagnostic value in assesement of case of tubercular pleural effusion. In country like us where diagnostic parameters like PCR, biopsy, culture, biochemical analysis are not always available in all centres of peripheral and remote areas, LN ratio can be used for simple and easy tool for diagnosis of tubercular effusion and furthermore in the well equipped centres where all diagnostic facilities are available it will be good supportive test for tubercular pleural effusion adding more accuracy with ADA level.

\section{CONCLUSION}

From the above discussion, it is concluded that pleural fluid $\mathrm{L} / \mathrm{N}$ ratio $>0.75$ is an efficient means of diagnosing tuberculous pleural effusion and its combination with ADA level gives us more accuracy and surety about the diagnosis of tubercular pleural effusion.

\section{LIMITATIONS OF THE STUDY}

The sample was taken from a medical college of eastern Nepal, so it may not be totally applicable to other regions . Moreover, larger sample size could have given little different results. Calculation of LNR values seemed to be more helpful in tubercular pleural effusion compared to malignant, parapneumonic and para-malignant effusions, so the potential use of this formula may be limited to countries with high TB incidence. An additional limitation of our study was that we only used LNR values; adding other parameters, such as, CRP levels, TB IgM to the evaluation could be more helpful for differential diagnosis.

\section{ACKNOWLEDGEMENTS}

I am very much thankful to Mr Bijay Kumar Jha for helping me in statistics and analyzing the results.

\section{CONFLICT OF INTEREST}

None

\section{FINANCIAL DISCLOSURE}

None

\begin{tabular}{lll} 
ISSN: 2542-2758 (Print) 2542-2804 (Online) & Birat Journal of Health Sciences \\
\hline 1520 & Vol.6/No.2/Issue 15/May-Aug., 2021
\end{tabular}




\section{REFERENCES}

1. Lesely J. Burgees, Frans J.M., Frans T.Comparative Analysis of the Biochemical Parameters Used to Distinguish Between Pleural Transudates and Exudates. Doi.org/10.1378/chest.107.6.1604.

2. Prabhudesai P P, Mahashur A A, Mehta N, Ajay R. Exudative pleural effusions in patients over forty years of age--an analysis of seventysix patients. J Postgrad Med 1993;39:190.

3. Porcel, J.M. Tuberculous Pleural Effusion. Lung187, 263 (2009). doi.org/10.1007/s00408-009-9165-3

4. Lakhotia M, Shah PK, Yadav A, Gupta A, Modi RK, Sinha HV. Comparison of biochemical parameters in pleural effusion.J Assoc Physicians India. 1996;44(9):612-614.

5. Alexandrakis MG, Kyriakou D, Alexandraki R, Pappa K, A, Antonakis N et. al: Pleural Interleukin-1 $\beta$ in Differentiating Transudates and Exudates: Comparative Analysis with Other Biochemical Parameters. Respiration 2002;69:201-206. doi: 10.1159/000063620

6. San José ME, Valdés L, Vizcaíno LH, Mora T, Pose A, et al. Procalcitonin, C-Reactive Protein, and Cell Counts in the Diagnosis of Parapneumonic Pleural Effusions. Journal of Investigative Medicine 2010;58:971-976.

7. Mehta AA, Gupta AS, Ahmed S, Rajesh V. Diagnostic utility of adenosine deaminase in exudative pleural effusions. Lung India. 2014;31(2):142-144. doi:10.4103/0970-2113.129842

8. Bhoumik, S., Rahman, M., Ibrahim, M., Hiron, M., \&Ahamad, M. Evaluation of Adenosine Deaminase (ADA) Activity for Diagnosis of Tubercular Pleural Effusion.Bangladesh Journal of Medical Biochemistry, 2014;6(2); 40-48.doi.org/10.3329

9. Shin MK, Ham HS, Lee DW, Cho YJ,JiongYYetal.The Diagnostic Usefulness of Pleural Fluid Adenosine deaminase with Lymphocyte/ Neutrophil Ratio in Tuberculous Pleural Effusion..TubercRespir Dis. 2004;57(2):132-137. doi.org/10.4046/trd.2004.57.2.132

10. Rahman F, Md. Zafar E, Prasad KR,Anand P, Arya ML. Study of adenosine deaminase and lymphocyte/neutrophil ratio in combination as diagnostic tool for tubercular pleural effusion. Journal of Evolution of Medical and Dental Sciences; 2015;4(88): 15365.

11. Zhai K, Lu Y, Shi HZ. Tuberculous pleural effusion.J Thorac Dis. 2016;8(7):486-E494. doi:10.21037/jtd.2016.05.87
12. Cohen LA, Light RW. Tuberculous Pleural Effusion.Turk Thorac J. 2015;16(1):1-9. doi:10.5152/ttd.2014.001

13. National Tuberculosis Programme: Ministry of Health, His Majesty's Government of Nepal: Tuberculosis Control in Nepal 2076/077.Long Term Plan. HMG, 2020.

14. Porcel JM. Tuberculous pleural effusion. Lung. 2009;187(5):263-70. doi.org/10.1007/s00408-009-9165-3

15. Bielsa S, Salud A, Martínez M, Esquerda A, MartínA,et al. Prognostic significance of pleural fluid data in patients with malignant effusion. European Journal of Internal Medicine .2008;9(5):334-339. doi.org/ 10.1016/j.ejim.2007.09.014.

16. BernesTW, OlsonEJ, Morgenth alert TI, EdsonRS, Decker PA et al. Low Yield of Microbiologic Studies on Pleural Fluid Specimens. CHEST. 2005;127(3):916-921.

17. NageshBS, Shova S, Surinder KJ, Sunil KA. Evaluation of Polymerase Chain Reaction for Detection of Mycobacterium tuberculosis in Pleural Fluid.CHEST;2001;119(6):1737-1741. doi.10.1378/ chest. 119.6.1737

18. Emmet E. Mc Grath, David Warriner, Paul B. Anderson. Pleural fluid characteristics of tuberculous pleural effusions, Heart\& Lung, 2010;39(6); 540-543.doi.org/10.1016/j.hrtlng.2009.12.004.

19. Lesley J. Burgess, Frans J. Maritz, Irene Le Roux, J.J. Frans Taljaard. Combined Use of Pleural Adenosine Deaminase With Lymphocyte/ Neutrophil Ratio: Increased Specificity for the Diagnosis of Tuberculous Pleuritis,Chest;109(2);414-419.doi.org/10.1378/ chest.109.2.414.

20. Ocaña I, Vazquez M, SeugeraRosa M., Fernandez-De-Sevilla T, Capdevila J A, Adenosine Deaminase in Pleural Fluids: Test for Diagnosis of Tuberculous Pleural Effusion, Chest;84(1);51-.doi.org/ 10.1378/chest.84.1.51.

21. Valdés L, San José SM, Pose A,Gude F, Francisco J. Et al. Diagnosing tuberculous pleural effusion using clinical data and pleural fluid analysis: A study of patients less than 40 years-old in an area with a high incidence of tuberculosis, Respiratory Medicine;104(8);121117.doi.org/10.1016/j.rmed.2010.02.025. 